\title{
Self-perceived neighborhood factors and OHRQoL among adolescents: a population-based study in southern Brazil
}

\author{
Ângela DALLA NORA ${ }^{(a)}$ iD \\ Jéssica Klöckner KNORST(a) \\ Letícia Donato COMIM(b) (iD) \\ Débora Nunes de Oliveira \\ RACKI(b) iD \\ Luana Severo ALVES(b) (iD \\ Júlio Eduardo do Amaral \\ ZENKNER $^{(a)}$ \\ (a) Universidade Federal de Santa Maria - \\ UFSM, School of Dentistry, Department of \\ Stomatology, Santa Maria, RS, Brazil. \\ (b) Universidade Federal de Santa Maria - \\ UFSM, School of Dentistry, Department \\ of Restorative Dentistry, Santa Maria, \\ RS, Brazil.
}

Declaration of Interests: The authors certify that they have no commercial or associative interest that represents a conflict of interest in connection with the manuscript.

Corresponding Author:

Luana Severo Alves

E-mail: luanaseal@gmail.com

https://doi.org/10.1590/1807-3107bor-2022.vol36.0003

\begin{abstract}
This study aimed to assess the relationship between self-perceived neighborhood factors and oral health-related quality of life (OHRQoL) among adolescents from southern Brazil. A representative sample of 15-19-year-old students from Santa Maria, Brazil, was included. The Oral Health Impact Profile (OHIP-14) was used to assess the OHRQoL. Self-perceived neighborhood factors were assessed through a structured questionnaire and included characteristics of the neighborhood where the adolescents lived, such as the presence of paved streets, tap water, community social networks, and availability of dental services and the Family Health Strategy (FHS). In addition, socioeconomic, behavioral, and clinical variables (dental caries and malocclusion) were also evaluated. Multilevel Poisson regression analysis with a hierarchical approach was used to assess the association between predictors and OHIP-14. The rate ratio (RR) and 95\% confidence intervals (CIs) were estimated. A total of 1,197 adolescents were included in this study (participation rate: $72.3 \%$ ). The mean OHIP-14 score was 8.4 (standard error $=0.2$ ), ranging from 0 to 49 . Living in residences with unpaved streets $(\mathrm{RR}=1.11$, 95\%CI:1.06-1.17), no tap water ( $R R=1.11,95 \% C I$ : $1.02-1.20)$, absence of the FHS services ( $R R=1.15,95 \% \mathrm{CI}$ : $1.09-1.20)$, and the availability of dental services ( $R R=1.08,95 \% \mathrm{CI}$ : $1.03-1.14)$ were associated with higher OHIP-14 scores, indicating a poorer OHRQoL. In addition, lower socioeconomic status, visiting the dentist for curative reasons, lower frequency of brushing teeth, and higher sugar consumption were also associated with higher OHIP-14 scores. In conclusion, self-perceived neighborhood characteristics were associated with OHRQoL in adolescents. Adolescents who perceived their neighborhood as deprived had poorer OHRQoL.
\end{abstract}

Keywords: Adolescent; Dental Caries; Quality of Life;

Residence Characteristics.

\section{Introduction}

Epidemiological studies on oral pathologies have surpassed the scrutiny of clinical signs. Repercussions of oral diseases not only impact
Submitted: February 2, 2021

Accepted for publication: June 21, 2021

Last revision: July 7, 2021 
physical well-being but extend to emotional, mental, economic, and social contexts. ${ }^{1}$ Apart from biological and behavioral factors, prevalence, severity, and progression rates of diseases are also influenced by social determinants ${ }^{2,3}$ that shape and maintain social hierarchies through social and political mechanisms. ${ }^{4}$

The assessment of the impact of oral diseases has been focused on distal factors and subjective measures of oral health, ${ }^{1,5}$ such as the oral health-related quality of life (OHRQoL). The literature has shown an inverse association between oral disease prevalence and OHRQoL. ${ }^{6,7}$ It is clear that socioeconomic status influences this relationship and low educational levels, low family incomes, and poor access to health services increase the negative impact of oral conditions on the quality of life. ${ }^{8}$ Considering that living and working conditions of individuals are related to health outcomes, ${ }^{2}$ previous studies have investigated the association between variables at the neighborhood level and OHRQoL in different populations. However, most studies on adolescents have focused on variables at school-level ${ }^{9,10}$ or restricted to the neighborhood's socioeconomic status and social support. ${ }^{11,12}$ Very few studies have included other neighborhood variables and their impact on adolescents. In addition, most studies addressing the association between neighborhood factors and oral health outcomes use contextual data derived from official sources, ${ }^{9-12}$ and little is known about the adolescents' self-perception of these factors.

OHRQoL represents a dynamic construct that may change over time. ${ }^{13,14}$ The transition from adolescence to adulthood is an important period in which quality of life may be affected. During this period, individuals become responsible for their self-care and are subject to their choices..$^{15}$ Thus, socio-environmental factors can affect health-related behaviors. The result of this interaction can influence clinical and behavioral measures that persist throughout the life of an individual. ${ }^{16}$ Considering the need for further evidence on this issue, this study investigated the relationship between self-perceived neighborhood factors and OHRQoL among adolescents from southern Brazil. We hypothesized that adolescents who perceived that they were from a poorer neighborhood had poorer OHRQoL.

\section{Methodology}

A population-based cross-sectional study assessed the oral health status of 15-19-year-old students from Santa Maria, a mid-sized city in southern Brazil. The study protocol was approved by the Research Ethics Committee of the Federal University of Santa Maria (CAAE 69901917.5.0000.5346). In addition, written informed consent was obtained from all the participants or their parents or legal guardians This study followed the STROBE statement. ${ }^{17}$

\section{Sample}

Students born between 1999 and 2003 attending any school period (morning, afternoon, or night) from all 37 public and private urban high schools (26 public and 11 private) in Santa Maria were considered eligible for the study. A simple random sampling strategy was used, considering the enrolled students as the survey unit. Participants were randomly selected in proportion to the school size using a table of random numbers. Students using fixed orthodontic appliances or those with special needs were not considered eligible.

The sample size was calculated using the following parameters: prevalence of 50\% (worst-case scenario), $95 \%$ confidence interval $(\mathrm{CI})$, power of $80 \%$, and precision level of $3 \%$. It was estimated that 1,066 students would be required, to which a non-participation rate of $50 \%$ was added, totaling 1,600 adolescents to be invited to participate. This sample is far more than required to estimate a difference between Oral Health Impact Profile-14 (OHIP-14) means of 11.9 (standard deviation $[\mathrm{SD}]=11.8$ ) in the exposed group (poor social context) and $8.4(\mathrm{SD}=7.0)$ in the unexposed group (better social context), as previously described. ${ }^{18}$

\section{Data collection}

Data were collected from March to November of 2018. First, a questionnaire on self-perceived neighborhood factors and socioeconomic and demographic characteristics was completed by adolescents.

Self-perceived neighborhood factors included characteristics of the neighborhood where the adolescents lived and were chosen based on a theoretical framework and previous literature on this topic. ${ }^{2,3,11,12,19}$ The characteristics of the neighborhood 
included the absence or presence of the following: paved streets (cobblestone, asphalt, or concrete roads), tap water (treated and supplied by the sanitation company), community centers, religious centers, availability of dental services, existence of the Family Health Strategy (FHS) services, and an area designated for physical activities. The FHS is a government program that focuses on primary healthcare. It is composed of a multi-professional team, which aims to improve the quality of life by following families more closely and intervening in the risk factors for diseases. Residences/neighborhoods covered by FHS receive home visits by health professionals regularly.

Socioeconomic variables included were as follows: maternal education (Selementary school, high school, or university); family income, measured through the Brazilian minimum wage (1 BMW corresponded to approximately USD 250 during the period of data collection) and dichotomized as $\leq 2 \mathrm{BMW}$ or $>2 \mathrm{BMW}$; and household crowding, categorized as low ( $\leq 1$ person/room), medium $(>1$ and $\leq 2$ persons/room), or high (> 2 persons/room). Demographic variables included sex (boys or girls), age ( $\leq 16$ years or $\geq 17$ years), and skin color (white or non-white).

Another questionnaire was administered to the adolescents to gather data on behavioral variables and OHRQoL. Behavioral variables included the reason for the last visit to the dentist (control/prevention/others or pain/restoration/extraction), frequency of brushing teeth (Sonce a day, twice a day, or $\geq 3$ times a day), and consumption of sugar-sweetened drinks ( $\leq$ twice a day, 3-4 times a day, 5-6 times a day, or $\geq 7$ times a day). The OHIP-14 was used to evaluate OHRQoL. ${ }^{20,21}$ It is a valid, reliable, and widely used instrument to assess the impact of oral conditions on OHRQoL. It includes seven subscales related to functional limitation, physical pain, psychological discomfort, physical disability, psychological disability, social disability, and handicap. ${ }^{20,21}$

Clinical examinations were conducted at schools using air compressor, artificial light, clinical mirrors, and periodontal probes (ballpoint/WHO). The adolescents were placed in a supine position over the school desks. After tooth cleaning and drying, the adolescents were examined by two trained and calibrated examiners for dental caries (DMFT) ${ }^{22}$ and malocclusion (DAI). ${ }^{22}$
Examiners' reliability was assessed before the beginning of the study and over the data collection period by reexamining $5 \%$ of the sample. The minimum kappa value for DMFT and the minimum intraclass correlation coefficient for DAI were both 0.80 .

\section{Data analysis}

Data analysis was performed using STATA software (Stata 14.2, Stata Corporation, College Station, USA). A weight variable based on the probability of selection and population distribution was used in the statistical analysis according to sex and school type. The weight variable was placed using the "svy" command for complex data samples.

The outcome of this study was OHRQoL, modeled as a count variable (OHIP-14 score). Preliminary analysis comparing the mean OHIP-14 scores among categories of predictors was carried out using the Wald test. Multilevel Poisson regression analysis was used to assess the association between predictors and OHIP-14 scores, considering adolescents as the first-level unit and neighborhoods (collected from the adolescents' addresses) as the second-level unit. The multilevel model used the scheme of fixed effects with a random intercept. In addition, a multilevel hierarchical analysis was performed based on a contextual framework (Figure 1) adapted from the WHO. ${ }^{23}$ Four models were described: Model 1 ("empty model") was an unconditional model; Model 2 included self-perceived neighborhood variables related to neighborhood characteristics; Model 3 was composed of Model 2 plus individual socioeconomic and demographic characteristics; and Model 4 was composed of Model 3 plus behavioral and clinical variables. All variables with $p<0.20$ in the unadjusted analysis were included in the adjusted analysis. In all models, the deviance (- $2 \log$ likelihood) was measured to assess the quality of fit. The results are presented as rate ratios (RRs) and 95\%CIs.

\section{Results}

A total of 1,197 15-19-year-old individuals were included in the study (participation rate $72.3 \%$ ). The main reason for non-participation was a lack of signed consent. As six schools refused to take 
part in the study (two private and four public), the number of students to be selected in each school was proportionally adjusted in the 31 participating schools to reach the necessary sample size. A flowchart of this study is shown in Figure 2.

Table 1 presents the characterization of the sample, the mean OHIP-14 scores by predictors, and the unadjusted multilevel Poisson regression analysis.
Overall, the mean OHIP-14 score was 8.2 (standard error $=0.2$ ), ranging from 0 to 49 . No significant difference was detected in the self-perceived neighborhood variables. Notwithstanding, all of them were significantly associated with OHIP14 scores in the unadjusted analysis, except for the availability of dental services and the presence of an area for physical activities. $1^{\circ}$ Block

\begin{tabular}{|c|c|}
\hline $\begin{array}{l}\text { Contextual-level } \\
\text { - Paved street } \\
\text { - Tap water } \\
\text { - Workers' center } \\
\text { - Religious center } \\
\text { - Family Health Strategy } \\
\text { - Availability of dental services } \\
\text { - Physical activity place }\end{array}$ & $\begin{array}{l}\text { Individual-level } \\
\text { Socioeconomic } \\
\text { characteristics } \\
\text { - Maternal education } \\
\text { - Family income } \\
\text { - Household crowding } \\
\text { Demographic } \\
\text { characteristics } \\
\text { - Sex } \\
\text { - Age } \\
\text { - Skin color }\end{array}$ \\
\hline
\end{tabular}

Structural social determinants $3^{\circ}$ Block

Behavioral variables
- Visit to dentist in the
last $6 \mathrm{~m}$
- Toothbrushing frequency
- Sugar-sweetened drink
consumption
Oral health variables
- Dental caries
- Malocclusion
Intermediary social
determinants

Outcome

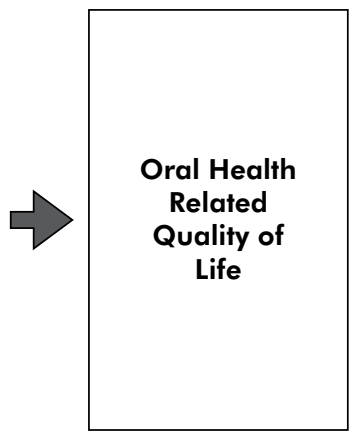

Figure 1. Theoretical model for the study of determinants of OHRQoL in adolescents, adapted from Word Health Organization. ${ }^{23}$

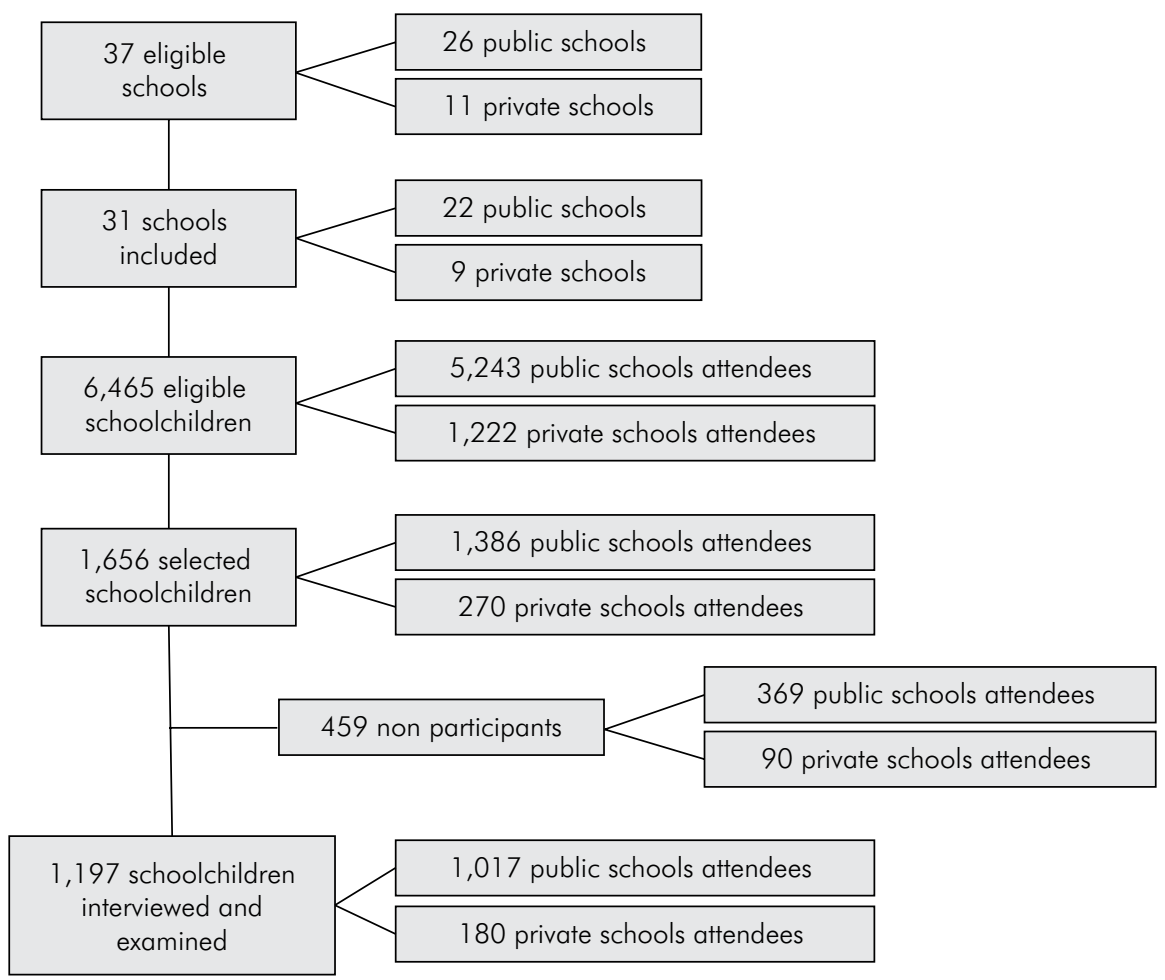

Figure 2. Flowchart of the study. 
Table 1. Characteristics of sample, mean OHIP-14 scores, and the unadjusted association between explanatory variables and OHIP-14 scores ( $n=1,197)$.

\begin{tabular}{|c|c|c|c|c|}
\hline Variable & n (\%) & Mean (SE) & $\operatorname{RR}(95 \% \mathrm{CI})^{*}$ & p-value \\
\hline \multicolumn{5}{|c|}{ Contextual-level variables (Neighborhood) } \\
\hline \multicolumn{5}{|l|}{ Paved street ${ }^{\dagger}$} \\
\hline Yes & $704(60.7)$ & $7.8(0.3)^{a}$ & 1.00 & \\
\hline No & $456(39.3)$ & $8.7(0.4)^{a}$ & $1.11(1.06-1.16)$ & $<0.001$ \\
\hline \multicolumn{5}{|l|}{ Tap water ${ }^{\dagger}$} \\
\hline Yes & $1,074(91.9)$ & $8.2(0.3)^{a}$ & 1.00 & \\
\hline No & $95(8.1)$ & $8.3(0.8)^{a}$ & $1.10(1.02-1.20)$ & 0.01 \\
\hline \multicolumn{5}{|l|}{ Community center ${ }^{\dagger}$} \\
\hline Yes & $338(28.8)$ & $8.0(0.4)^{a}$ & 1.00 & \\
\hline No & $836(71.2)$ & $8.3(0.3)^{a}$ & $1.05(1.00-1.11)$ & 0.03 \\
\hline \multicolumn{5}{|l|}{ Religious Center ${ }^{\dagger}$} \\
\hline Yes & $1,038(88.4)$ & $8.1(0.2)^{\mathrm{a}}$ & 1.00 & \\
\hline No & $136(11.6)$ & $8.7(0.8)^{a}$ & $1.09(1.02-1.16)$ & 0.01 \\
\hline \multicolumn{5}{|l|}{ Family Health Strategy ${ }^{\dagger}$} \\
\hline Yes & $483(41.1)$ & $7.9(0.3)^{a}$ & 1.00 & \\
\hline No & $691(58.9)$ & $8.5(0.3)^{a}$ & $1.13(1.08-1.18)$ & $<0.001$ \\
\hline \multicolumn{5}{|c|}{ Availability of dental services ${ }^{\dagger}$} \\
\hline No & $693(59.0)$ & $8.2(0.3)^{a}$ & 1.00 & \\
\hline Yes & $481(41.0)$ & $8.3(0.5)^{a}$ & $1.04(0.99-1.08)$ & 0.09 \\
\hline \multicolumn{5}{|l|}{ Physical activity place ${ }^{\dagger}$} \\
\hline Yes & $687(58.5)$ & $8.1(0.3)^{a}$ & 1.00 & \\
\hline No & $487(41.5)$ & $8.3(0.4)^{a}$ & $1.03(0.99-1.08)$ & 0.10 \\
\hline \multicolumn{5}{|c|}{ Individual-level variables (Adolescent) } \\
\hline \multicolumn{5}{|l|}{ Socioeconomic variables } \\
\hline \multicolumn{5}{|l|}{ Maternal education ${ }^{\dagger}$} \\
\hline University & $192(16.7)$ & $6.5(0.5)^{a}$ & 1.00 & \\
\hline High school & $380(33.1)$ & $8.2(0.4)^{b}$ & $1.25(1.17-1.34)$ & $<0.001$ \\
\hline$\leq$ Primary school & $577(50.2)$ & $8.7(0.3)^{b}$ & $1.27(1.18-1.35)$ & $<0.001$ \\
\hline \multicolumn{5}{|l|}{ Family income ${ }^{\dagger}$} \\
\hline$>2 \mathrm{BMW}$ & $509(45.8)$ & $7.0(0.3)^{a}$ & 1.00 & \\
\hline$\leq 2 \mathrm{BMW}$ & $602(54.2)$ & $9.4(0.3)^{b}$ & $1.30(1.24-1.35)$ & $<0.001$ \\
\hline \multicolumn{5}{|l|}{ Household crowding ${ }^{\dagger}$} \\
\hline Low & $275(23.9)$ & $7.3(0.4)^{a}$ & 1.00 & \\
\hline Medium & $751(65.3)$ & $8.1(0.3)^{a}$ & $1.09(1.03-1.15)$ & $<0.001$ \\
\hline High & $124(10.8)$ & $11.8(1.0)^{b}$ & $1.51(1.40-1.62)$ & $<0.001$ \\
\hline \multicolumn{5}{|l|}{ Demographic variables } \\
\hline \multicolumn{5}{|l|}{ Sex } \\
\hline Boys & $513(42.9)$ & $7.4(0.4)^{a}$ & 1.00 & \\
\hline Girls & $684(57.1)$ & $9.0(0.3)^{b}$ & $1.20(1.15-1.25)$ & $<0.001$ \\
\hline \multicolumn{5}{|l|}{ Age (years) } \\
\hline$\leq 16$ & $655(54.6)$ & $7.6(0.3)^{a}$ & 1.00 & \\
\hline$\geq 17$ & $544(45.4)$ & $9.1(0.4)^{b}$ & $1.19(1.15-1.24)$ & $<0.001$ \\
\hline \multicolumn{5}{|l|}{ Skin color ${ }^{\dagger}$} \\
\hline White & $779(67.0)$ & $7.9(0.3)^{\circ}$ & 1.00 & \\
\hline Non-white & $384(33.0)$ & $9.0(0.4)^{b}$ & $1.12(1.08-1.17)$ & $<0.001$ \\
\hline
\end{tabular}




\begin{tabular}{|c|c|c|c|c|}
\hline Variable & $\mathrm{n}(\%)$ & Mean (SE) & $\operatorname{RR}(95 \% \mathrm{Cl})^{*}$ & $\mathrm{p}$-value \\
\hline \multicolumn{5}{|l|}{ Behavioral variables } \\
\hline \multicolumn{5}{|c|}{ Reason of the last visit to the dentist } \\
\hline Control/prevention/others & $809(72.8)$ & $6.9(0.2)^{a}$ & 1.00 & \\
\hline Pain/restoration/extraction & $302(27.2)$ & $12.0(0.5)^{b}$ & $1.75(1.67-1.83)$ & $<0.001$ \\
\hline \multicolumn{5}{|l|}{ Tooth brushing frequency ${ }^{\dagger}$} \\
\hline$\geq 3$ times a day & $566(47.4)$ & $8.0(0.3)^{a}$ & 1.00 & \\
\hline Twice a day & $512(42.9)$ & $8.0(0.3)^{a}$ & $0.98(0.94-1.02)$ & 0.34 \\
\hline$\leq$ once a day & $116(9.7)$ & $10.2(0.8)^{b}$ & $1.24(1.16-1.32)$ & $<0.001$ \\
\hline \multicolumn{5}{|c|}{ Sugar-sweetened drink consumption ${ }^{\dagger}$} \\
\hline$\leq$ twice a day & $664(55.6)$ & $7.4(0.3)^{a}$ & 1.00 & \\
\hline 3-4 times a day & $380(31.8)$ & $8.5(0.4)^{b}$ & $1.13(1.08-1.18)$ & $<0.001$ \\
\hline $5-6$ times a day & $100(8.4)$ & $10.7(0.7)^{\mathrm{bc}}$ & $1.37(1.28-1.46)$ & $<0.001$ \\
\hline$\geq 7$ times a day & $51(4.3)$ & $12.2(2.1)^{\mathrm{b}}$ & $1.62(1.48-1.76)$ & $<0.001$ \\
\hline \multicolumn{5}{|l|}{ Oral health variables } \\
\hline \multicolumn{5}{|l|}{ Dental caries } \\
\hline $\mathrm{DMFT}=0$ & $641(53.6)$ & $6.8(0.3)^{a}$ & 1.00 & \\
\hline DMFT $\geq 1$ & $556(46.4)$ & $9.9(0.4)^{b}$ & $1.47(1.42-1.54)$ & $<0.001$ \\
\hline \multicolumn{5}{|l|}{ Malocclusion } \\
\hline $\mathrm{DAl} \leq 25$ & $293(24.5)$ & $7.0(0.2)^{a}$ & 1.00 & \\
\hline $\mathrm{DAl}>25$ & $904(75.5)$ & $8.7(0.3)^{\mathrm{b}}$ & $1.26(1.20-1.32)$ & $<0.001$ \\
\hline TOTAL & 1,197 (100.0) & $8.4(0.2)$ & & \\
\hline
\end{tabular}

SE: Standard error; Cl: Confidence interval; RR: rate ratio; BMW: Brazilian minimum wage (1 BMW corresponded to approximately USD 250 during the period of data collection); DMFT: decayed, missing, and filled teeth index; DAl: Dental aesthetic index. † Missing data. *Multilevel Poisson regression analysis. Different letters indicate statistically significant difference between categories (Wald test, $p<0.05)$.

The adjusted multilevel Poisson models using a hierarchical approach are presented in Table 2. As shown in Model 2, living in residences with unpaved streets $(\mathrm{RR}=1.11 ; 95 \% \mathrm{CI}: 1.06-1.17)$, no tap water $(\mathrm{RR}=1.11$; 95\%CI: 1.02-1.20), absence of the FHS (RR $=1.15$; 95\%CI: 1.09-1.20), and availability of dental services $(\mathrm{RR}=1.08$; 95\%CI: $1.03-1.14)$ were associated with higher OHIP-14 scores. Model 3 shows that indicators of low socioeconomic status and demographic variables (girls, older, and non-white) were associated with poorer OHRQoL. In addition, as shown in Model 4, adolescents reporting a lower frequency of brushing teeth, higher frequency of consumption of sugar-sweetened drinks, and those with dental caries and malocclusion reported higher OHIP-14 scores.

\section{Discussion}

This population-based study was conducted to assess the effects of self-perceived neighborhood variables on the OHRQoL of 15-19-year-old South Brazilian adolescents. Our main result was that living in neighborhoods with a low urban framework, lesser access to public health policies, and availability of dental services were associated with poorer OHRQoL. Moreover, sociodemographic, behavioral, and clinical factors were also associated with poorer OHRQoL.

Adolescents living in residences with unpaved streets and no tap water had a poorer OHRQoL than their counterparts. The urban environment, providing basic housing resources to the population, plays a fundamental role in building community well-being. ${ }^{24}$ Access to education, health care facilities, jobs, and a safe environment are strong determinants of community health..$^{25}$ The lack of paved streets and tap water is related to poor conditions of sanitation, security, accessibility, and unhealthy environment, which are hallmarks that describe social inequality. ${ }^{26}$ Furthermore, the lack of tap water deprives adolescents of fluoridated water, which is a determinant of the 
Table 2. Adjusted association between explanatory variables and OHIP-14 scores. Multilevel Poisson regression analysis.

\begin{tabular}{|c|c|c|c|c|}
\hline \multirow{2}{*}{ Variable } & Model $1^{a}$ & Model $2^{b}$ & Model 3c & Model $4^{\mathrm{d}}$ \\
\hline & $\operatorname{RR}(95 \% \mathrm{Cl})$ & $\operatorname{RR}(95 \% \mathrm{Cl})$ & $\operatorname{RR}(95 \% \mathrm{Cl})$ & $\mathrm{RR}(95 \% \mathrm{Cl})$ \\
\hline \multicolumn{5}{|l|}{ Fixed component } \\
\hline Intercept & $8.28(7.73-8.87)^{*}$ & $6.62(6.02-7.27)^{*}$ & $4.07(3.61-4.57)^{*}$ & $2.88(2.46-3.38)^{*}$ \\
\hline \multicolumn{5}{|c|}{ Contextual-level variables (Neighborhood) } \\
\hline \multicolumn{5}{|l|}{ Paved street (ref. Yes) } \\
\hline No & & $1.11(1.06-1.17)^{*}$ & $1.06(1.00-1.11)$ & $1.01(0.96-1.07)$ \\
\hline \multicolumn{5}{|l|}{ Tap water (ref. Yes) } \\
\hline No & & $1.11(1.02-1.20)^{*}$ & $1.09(0.99-1.19)$ & $1.16(1.05-1.27)$ \\
\hline \multicolumn{5}{|l|}{ Community center (ref. Yes) } \\
\hline No & & $1.03(0.98-1.09)$ & $1.04(0.99-1.10)$ & $1.02(0.97-1.08)$ \\
\hline \multicolumn{5}{|l|}{ Religious Center (ref. Yes) } \\
\hline No & & $1.07(1.00-1.14)$ & $1.1(1.03-1.19)$ & $1.07(0.99-1.15)$ \\
\hline \multicolumn{5}{|l|}{ Family Health Strategy (ref. Yes) } \\
\hline No & & $1.15(1.09-1.20)^{*}$ & $1.17(1.11-1.22)$ & $1.18(1.12-1.24)$ \\
\hline \multicolumn{5}{|c|}{ Availability of dental services (ref. No) } \\
\hline Yes & & $1.08(1.03-1.14)^{*}$ & $1.05(1.00-1.11)$ & $1.06(1.01-1.12)$ \\
\hline \multicolumn{5}{|l|}{ Physical activity place (ref. Yes) } \\
\hline No & & $1.02(0.97-1.07)$ & $0.97(0.92-1.02)$ & $1.02(0.96-1.08)$ \\
\hline \multicolumn{5}{|l|}{ Individual-level variables (Adolescent) } \\
\hline \multicolumn{5}{|l|}{ Socioeconomic variables } \\
\hline \multicolumn{5}{|c|}{ Maternal education (ref. University) } \\
\hline High school & & & $1.13(1.05-1.21)^{*}$ & $1.07(0.99-1.15)$ \\
\hline$\leq$ Primary school & & & $1.10(1.02-1.19)^{*}$ & $1.04(0.96-1.12)$ \\
\hline \multicolumn{5}{|l|}{ Family income (ref. > 2 BMW) } \\
\hline$\leq 2 \mathrm{BMW}$ & & & $1.26(1.21-1.33)^{*}$ & $1.18(1.12-1.24)$ \\
\hline \multicolumn{5}{|l|}{ Household crowding (ref. Low) } \\
\hline Medium & & & $1.12(1.06-1.18)^{*}$ & $1.11(1.05-1.18)$ \\
\hline High & & & $1.44(1.33-1.56)^{*}$ & $1.41(1.30-1.53)$ \\
\hline \multicolumn{5}{|l|}{ Demographic variables } \\
\hline \multicolumn{5}{|l|}{ Sex (ref. Boys) } \\
\hline Girls & & & $1.20(1.15-1.26)^{*}$ & $1.24(1.17-1.30)$ \\
\hline \multicolumn{5}{|l|}{ Age (ref. $\leq 16$ years) } \\
\hline$\geq 17$ & & & $1.16(1.11-1.22)^{*}$ & $1.10(1.05-1.15)$ \\
\hline \multicolumn{5}{|l|}{ Skin color (ref. White) } \\
\hline Non-white & & & $1.06(1.01-1.12)^{*}$ & $1.07(1.02-1.13)$ \\
\hline \multicolumn{5}{|l|}{ Behavioral variables } \\
\hline \multicolumn{5}{|c|}{ Reason of the last visit to the dentist (ref. Control/prevention/others) } \\
\hline Pain/restoration/extraction & & & & $1.53(1.45-1.61)^{*}$ \\
\hline \multicolumn{5}{|c|}{ Tooth brushing frequency (ref. $\geq 3$ times a day) } \\
\hline Twice a day & & & & $0.94(0.89-0.98)^{*}$ \\
\hline$\leq$ once a day & & & & $1.26(1.16-1.36)^{*}$ \\
\hline \multicolumn{5}{|c|}{ Sugar-sweetened drink consumption (ref. $\leq$ twice a day) } \\
\hline $3-4$ times a day & & & & $1.09(1.03-1.15)^{*}$ \\
\hline $5-6$ times a day & & & & $1.31(1.21-1.42)^{*}$ \\
\hline$\geq 7$ times a day & & & & $1.43(1.29-1.58)^{*}$ \\
\hline
\end{tabular}




\begin{tabular}{|c|c|c|c|c|}
\hline \multirow{2}{*}{ Variable } & Model $1^{a}$ & Model $2^{b}$ & Model 3c & Model $4^{\mathrm{d}}$ \\
\hline & $\operatorname{RR}(95 \% \mathrm{Cl})$ & $\operatorname{RR}(95 \% \mathrm{CI})$ & $\operatorname{RR}(95 \% \mathrm{Cl})$ & RR (95\%Cl) \\
\hline \multicolumn{5}{|l|}{ Oral health variables } \\
\hline \multicolumn{5}{|c|}{ Dental caries (ref. DMFT=0) } \\
\hline $\mathrm{DMFT} \geq 1$ & & & & $1.25(1.19-1.31)^{*}$ \\
\hline \multicolumn{5}{|c|}{ Malocclusion (ref. DAI $\leq 25$ ) } \\
\hline $\mathrm{DAl}>25$ & & & & $1.19(1.12-1.26)^{*}$ \\
\hline \multicolumn{5}{|l|}{ Random component } \\
\hline Deviance (-2 loglik) & 11560.09 & 11097.42 & 9351.64 & 7930.92 \\
\hline
\end{tabular}

aodel 1: empty model, unconditional model; 'bodel 2: model 1 adjusted for contextual variables; 'Model 3: model 2 adjusted for contextual, demographic, and socioeconomic variables; ${ }^{M}$ Model 4: fully adjusted for contextual, demographic, socioeconomic, behavioral, and oral health variables. RR: rate ratio; Cl: confidence interval; BMW: Brazilian minimum wage (1 BMW corresponded to approximately USD 250 during the period of data collection); ${ }^{*}$-value $<0.05$.

caries decline observed at the population level. ${ }^{27}$ Thus, oral diseases mainly affect disadvantaged and socially marginalized populations and, consequently, their OHRQoL. This finding is aligned with those of the previous studies. ${ }^{914,28,29}$ A 2-year Brazilian cohort study indicated that a lower mean income of the school's neighborhood, household income, and maternal schooling affected OHRQoL over time. ${ }^{12}$ Residents of neighborhoods with lower socioeconomic status faced a higher risk of premature mortality, which further provides evidence of the impact of neighborhood contextual factors on health outcomes, even in developed countries. ${ }^{30}$. Thus, places of residence seem to be a strong predictor of OHRQoL. ${ }^{31}$ In this context, planning and performing oral health promotion strategies should consider the influence of the neighborhood environment on individual responses to oral disease and their coping methods. ${ }^{14}$

Adolescents who perceived the absence of FHS in their neighborhood were $15 \%$ more likely to report a poorer OHRQoL than those who reported the presence of this service. The promotion of home visits by health professionals is one of the key actions of the FHS, and we can presume that easy access to information on both general and oral health care may explain our findings of a better OHRQoL. In contrast, adolescents living in neighborhoods without FHS services are not given enough information about healthy habits and behaviors. In addition, health professionals from FHS follow families closely and intervene when potential risk factors for diseases are detected. Hence, the presence of FHS services may also positively affect OHRQoL, because it allows early detection of diseases and referral to dental services thereby, decreasing the treatment costs and disease extension. ${ }^{32}$ It should be highlighted that not all FHS services have a dental professional in the team. However, the presence of the service itself may have a positive effect on oral health and OHRQoL, since general recommendations on breastfeeding, healthy dietary habits, and general hygiene may affect the behaviors and practices of the family and ultimately benefit oral health.

Adolescents who lived in neighborhoods with the availability of dental services presented higher OHIP14 scores than those who reported the absence of dental services. This can be explained by the "Inverse Care Law", according to which both the amount of care available and the quality of care provided are inversely related to the need..$^{33}$ Individuals with greater needs are often unable to access services, further affecting their OHRQoL. The notion that the availability of a health care service in the neighborhood could be translated into a) access, b) services of quality, and c) better OHRQoL proved to be a misconception in this population. In addition, it is possible to speculate that the profile of the dental service available in the neighborhood may influence its association with OHRQoL, whether preventive, operative, aimed at emergency care, focused on primary level care, or specialized treatment, among others.

Social networks formed at religious and community centers play an important role in influencing the social support system and oral health of a community. 
However, these self-perceived neighborhood variables were not associated with OHRQoL among South Brazilian adolescents. The lack of community and religious centers in the neighborhood negatively affected the OHRQoL of adolescents in the unadjusted analysis; however, after adjusting for other factors, these associations lost the statistical significance. This finding could be related to the age of the population in this study. During adolescence and young adulthood, individuals continue to build interpersonal relationships, and social networks may be more easily built between family members, friends, and schoolmates ${ }^{34}$ rather than at community and religious centers.

This study is important because we have evaluated the several factors that can influence OHRQoL, such as self-perceived neighborhood characteristics, sociodemographic, behavioral, and clinical factors. Considering that an individual's perception of a service/association/structural factor in a neighborhood may not always match the official sources, this information was individually collected by a questionnaire. Therefore, we presumed that the self-perception of each adolescent would be more meaningful for the study than the neighborhood data collected from official sources. All urban, public, and private schools were invited to participate in the study, and the vast majority agreed to participate (31 out of 37). Although six schools did not agree to participate, they were distributed proportionally according to school type and spread evenly throughout the city regions, thus ensuring the external validity of the data. In addition, the random allocation procedure comprised all schoolers in the morning, afternoon, and night school periods. Therefore, we consider our sample representative of the population. Furthermore, methodological issues such as examiners' reproducibility and the use of a validated questionnaire to measure OHRQoL provided a high internal validity to our study. Among the study limitations resides the fact that some questions of the neighborhood self-perception questionnaire may have been answered by adolescents' parents/ legal guardians, thus adding some degree of bias to the data. The exclusion of adolescents with fixed orthodontic appliances can also be a possible limitation of this study. Even considering their increased risk for caries development, ${ }^{35}$ we decided to exclude these individuals due to the additional difficulties imposed by the fixed apparatus to perform proper clinical examinations under field conditions. Moreover, we could assume some degree of ecological fallacy in data interpretation, considering that inferences about individuals were deduced from data about the neighborhood to which they belong. Finally, this study had a cross-sectional design and causal relationships could not be addressed.

In conclusion, this population-based cross-sectional study showed that self-perceived neighborhood characteristics were associated with OHRQoL in 15-19-year-old adolescents. Individuals who perceived their neighborhood as deprived had poorer OHRQoL. In addition, the availability of dental services was also associated with higher OHIP-14 scores. These findings are useful for implementing public health policies targeting structural factors, which can partly explain the reasons for inequalities in oral health and quality of life in this population.

\section{Acknowledgments}

We acknowledge the support of the National Coordination of Post-graduate Education (CAPES), Ministry of Education, Brazil (finance code 001), the Municipality Oral Health Policy of Santa Maria, and the Federal University of Santa Maria. We also would like to thank all volunteers, their parents/legal guardians, and the schools for their contribution.

\section{References}

1. Glick M, Williams DM, Kleinman DV, Vujicic M, Watt RG, Weyant RJ. A new definition for oral health developed by the FDI World Dental Federation opens the door to a universal definition of oral health. Br Dent J. 2016 Dec;221(12):792-3. https://doi.org/10.1038/si.bdj.2016.953

2. Solar O, Irwin A. A conceptual framework for action on the social determinants of health: social determinants of health discussion. Geneva: WHO Press; 2010. 
3. Marmot M, Bell R. Social determinants and dental health. Adv Dent Res. 2011 May;23(2):201-6. https://doi.org/10.1177/0022034511402079

4. Marmot M, Friel S, Bell R, Houweling TA, Taylor S. Closing the gap in a generation: health equity through action on the social determinants of health. Lancet. 2008 Nov;372(9650):1661-9. https://doi.org/10.1016/S0140-6736(08)61690-6

5. Locker D, Allen F. What do measures of 'oral health-related quality of life' measure? Community Dent Oral Epidemiol. 2007 Dec;35(6):401-11. https://doi.org/10.1111/j.1600-0528.2007.00418.x

6. Huang DL, Park M. Socioeconomic and racial/ethnic oral health disparities among US older adults: oral health quality of life and dentition. J Public Health Dent. 2015;75(2):85-92. https://doi.org/10.1111/iphd.12072

7. Vettore MV, Aqeeli A. The roles of contextual and individual social determinants of oral health-related quality of life in Brazilian adults. Qual Life Res. 2016 Apr;25(4):1029-42. https://doi.org/10.1007/s11136-015-1118-0

8. Mejia GC, Elani HW, Harper S, Murray Thomson W, Ju X, Kawachi I, et al. Socioeconomic status, oral health and dental disease in Australia, Canada, New Zealand and the United States. BMC Oral Health. 2018 Oct;18(1):176. https://doi.org/10.1186/s12903-018-0630-3

9. Alwadi MA, Vettore MV. Are school and home environmental characteristics associated with oral health-related quality of life in Brazilian adolescents and young adults? Community Dent Oral Epidemiol. 2017 Aug;45(4):356-64. https://doi.org/10.1111/cdoe.12298

10. Machry RV, Knorst JK, Tomazoni F, Ardenghi TM. School environment and individual factors influence oral health related quality of life in Brazilian children. Braz Oral Res. 2018 Jul;32(0):e63. https://doi.org/10.1590/1807-3107bor-2018.vol32.0063

11. Guedes RS, Piovesan C, Antunes JL, Mendes FM, Ardenghi TM. Assessing individual and neighborhood social factors in child oral health-related quality of life: a multilevel analysis. Qual Life Res. 2014 Nov;23(9):2521-30. https://doi.org/10.1007/s11136-014-0690-z

12. Sfreddo CS, Moreira CH, Nicolau B, Ortiz FR, Ardenghi TM. Socioeconomic inequalities in oral health-related quality of life in adolescents: a cohort study. Qual Life Res. 2019 Sep;28(9):2491-500. https://doi.org/10.1007/s11136-019-02229-2

13. Baker SR, Mat A, Robinson PG. What psychosocial factors influence adolescents' oral health? J Dent Res. 2010 Nov;89(11):1230-5. https://doi.org/10.1177/0022034510376650

14. Vettore MV, Ahmad SF, Machuca C, Fontanini H. Socio-economic status, social support, social network, dental status, and oral health reported outcomes in adolescents. Eur J Oral Sci. 2019 Apr;127(2):139-46. https://doi.org/10.1111/eos.12605

15. Sawyer SM, Afifi RA, Bearinger LH, Blakemore SJ, Dick B, Ezeh AC, et al. Adolescence: a foundation for future health. Lancet. 2012 Apr;379(9826):1630-40. https://doi.org/10.1016/S0140-6736(12)60072-5

16. Vettore MV, Faerstein E, Baker SR. Social position, social ties and adult's oral health: 13 year cohort study. J Dent. 2016 Jan;44:50-6. https://doi.org/10.1016/i.jident.2015.12.004

17. Vandenbroucke JP, von Elm E, Altman DG, Gøtzsche PC, Mulrow CD, Pocock SJ, et al. Strengthening the Reporting of Observational Studies in Epidemiology (STROBE): explanation and elaboration. Epidemiology. 2007 Nov;18(6):805-35. https://doi.org/10.1097/EDE.0b013e3181577511

18. Knorst JK, Menegazzo GR, Emmanuelli B, Mendes FM, Ardenghi TM. Effect of neighborhood and individual social capital in early childhood on oral health-related quality of life: a 7-year cohort study. Qual Life Res. 2019 Jul;28(7):1773-82. https://doi.org/10.1007/s11136-019-02138-4

19. Thomson WM, Williams SM, Broadbent JM, Poulton R, Locker D. Long-term dental visiting patterns and adult oral health. J Dent Res. 2010 Mar;89(3):307-11. https://doi.org/10.1177/0022034509356779

20. Slade GD. Derivation and validation of a short-form oral health impact profile. Community Dent Oral Epidemiol. 1997 Aug;25(4):284-90. https://doi.org/10.1111/j.1600-0528.1997.tb00941.x PMID:9332805

21. Oliveira BH, Nadanovsky P. Psychometric properties of the Brazilian version of the Oral Health Impact Profile-short form. Community Dent Oral Epidemiol. 2005 Aug;33(4):307-14. https://doi.org/10.1111/i.1600-0528.2005.00225.x

22. World Health Organization. Oral Health surveys: basic methods. Geneva: World Health Organization; 1997.

23. World Health Organization. A conceptual framework for action on the social determinants of health. Geneva: World Health Organization; 2010.

24. Graham H, White PC. Social determinants and lifestyles: integrating environmental and public health perspectives. Public Health. 2016 Dec;141:270-8. https://doi.org/10.1016/i.puhe.2016.09.019

25. Alves FN, Andrade CL, Vettore MV. Planning oral health care using the sociodental approach and the index of family living conditions: a cross-sectional study in Brazilian adolescents. BMC Res Notes. 2015 Oct;8(1):588. https://doi.org/10.1186/s13104-015-1564-3

26. Sisson KL. Theoretical explanations for social inequalities in oral health. Community Dent Oral Epidemiol. 2007 Apr;35(2):81-8. https://doi.org/10.1111/j.1600-0528.2007.00354.x

27. Whelton HP, Spencer AJ, Do LG, Rugg-Gunn AJ. Fluoride revolution and dental caries: evolution of policies for global use. J Dent Res. 2019 Jul;98(8):837-46. https://doi.org/10.1177/0022034519843495

28. Fonseca RC, Antunes JL, Cascaes AM, Bomfim RA. Analysis of the combined risk of oral problems in the oral health-related quality of life of Brazilian adolescents: multilevel approach. Clin Oral Investig. 2020 Feb;24(2):857-66. https://doi.org/10.1007/s00784-019-02976-z 
29. Celeste RK, Nadanovsky P, Ponce de Leon A, Fritzell J. The individual and contextual pathways between oral health and income inequality in Brazilian adolescents and adults. Soc Sci Med. 2009 Nov;69(10):1468-75. https://doi.org/10.1016/i.socscimed.2009.08.005

30. Khomenko S, Nieuwenhuijsen M, Ambròs A, Wegener S, Mueller N. Is a liveable city a healthy city? Health impacts of urban and transport planning in Vienna, Austria. Environ Res. 2020 Apr;183:109238. https://doi.org/10.1016/i.envres.2020.109238

31. Diez Roux AV, Mair C. Neighborhoods and health. Ann N Y Acad Sci. 2010 Feb;1186(1):125-45.

https://doi.org/10.1111/j.1749-6632.2009.05333.x

32. Feldens CA, Fortuna MJ, Kramer PF, Ardenghi TM, Vítolo MR, Chaffee BW. Family Health Strategy associated with increased dental visitation among preschool children in Brazil. Int J Paediatr Dent. 2018 Nov;28(6):624-32. https://doi.org/10.1111/ipd.12421

33. Harris RV. Do 'poor areas' get the services they deserve? The role of dental services in structural inequalities in oral health. Community Dent Health. 2016 Jun;33(2):164-7.

34. Camara M, Bacigalupe G, Padilla P. The role of social support in adolescents: are you helping me or stressing me out? Int J Adolesc Youth. 2007;22(2):123-36. https://doi.org/10.1080/02673843.2013.875480

35. Pinto AS, Alves LS, Maltz M, Zenkner JE. Association between fixed orthodontic treatment and dental caries: a 1-year longitudinal study. Braz Oral Res. 2020 Nov;35:e002. https://doi.org/10.1590/1807-3107bor-2021.vol35.0002 